\title{
COMPARATIVE CYTOTOXICITY ASSAYS PERFORMED USING A FREE PORPHYRIN AND ITS Zn(II), Co(II) AND Cu(II) COMPLEXES. INFLUENCE OF OPTICAL AND AGGREGATION PROPERTIES
}

\section{RADOSTINA ALEXANDROVA ${ }^{\mathrm{a},{ }^{*},}$ RENI KALFIN ${ }^{\mathrm{b}}$, RAMONA TUDOSE $^{\mathrm{c}}$, EUGENIA FAGADAR-COSMA ${ }^{\mathrm{c}, *}$}

\begin{abstract}
Our present approach is dealing with comparative cytotoxicity assays performed with a porphyrin base, substituted with methoxy-inductive donor substituents in the meso position, namely: 5,10,15,20-tetrakis-( $p$ methoxy-phenyl porphyrin (TMeOPP) and with its $\mathrm{Zn}(\mathrm{II}), \mathrm{Co}(\mathrm{II})$ and $\mathrm{Cu}(\mathrm{II})$ complexes (Figure 1). The cytotoxicity evaluation was performed using human (HeLa, 8 MGBA, Lep-3) and bovine (MDBK) cell lines as model systems. The influence of the compounds on cell viability and proliferation was studied by (thiazolyl blue tetrazolium bromide) MTT test and further discussed taking into consideration the main optical and aggregation properties of the free porphyrin and its different metal complexes.
\end{abstract}

Keywords: $\mathrm{Zn}(\mathrm{II}), \mathrm{Co}(\mathrm{II})$ and $\mathrm{Cu}(\mathrm{II})-$ metalloporphyrins, cytotoxicity evaluation, UV-vis spectroscopy, STEM microscopy, MTT test.

\section{INTRODUCTION}

Substituted meso-tetraarylporphyrins represent an amazing class of molecular building blocks due to their large size, extended aromatic $\pi$-system and high versatility for binding various transitional metal ions. Porphyrins successfully act as photosensitizers in noninvasive photodynamic therapy (PDT) treatments. Photosensitizers are molecules which when irradiated by

\footnotetext{
a Institute of Experimental Morphology, Pathology and Anthropology with Museum Bulgarian Academy of Sciences, Acad. G. Bonchev St., Block 25, 1113 Sofia, Bulgaria.

b Institute of Neurobiology, Bulgarian Academy of Sciences, Acad. G. Bonchev St., Block 23, 1113 Sofia, Bulgaria.

c Institute of Chemistry Timisoara of Romanian Academy, M. Viteazul Ave. 24, 300223-Timisoara, Romania.

*Corresponding author: efagadar@yahoo.com
} 
light energy in the presence of oxygen might induce photochemical reactions producing lethal cytotoxic agents, due to generated reactive singlet oxygen [1].

In order to facilitate PDT, second generation of porphyrin photosensitizers have to respond to some mandatory photochemical conditions: high absorption coefficient in the red visible region of the spectrum, mainly in the field (650$800 \mathrm{~nm}$ ) and a long lifetime of the triplet excited state in order to efficiently produce singlet molecular oxygen. In the absence of light and oxygen the photosensitizers have no effect on healthy or malignant cells and that is the reason why the time of light exposure has to be carefully monitored to ensure that the activation of the photosensitizer is occurring only when the ratio of the photosensitizer in neoplastic cells is higher than that localized in healthy tissue $[2,3]$.

The capacity of the free porphyrin to exist simultaneously in aggregated and protonated forms was previously investigated and brings significant influences on biological activity [4]. In this respect, experiments were focused to improve cellular uptake of the porphyrins acting as photosensitizers both by hindering their aggregation processes and by increasing their hydrophilicity [5]. A chlorin water-soluble conjugate with 4arylaminoquinazoline moiety was proven to be suitable for photodynamic therapy (PDT), exhibiting dark and photoinduced cytotoxicity at very low micromolar concentrations (IC50dark/IC50light ratio of 11-18), and prefers to accumulate in the tumor tissue [6].

The metallic complexes of methoxy-substituted tetraphenylporphyrins are well known for their capacity to bind axial ligands which increase their chemical versatility and enable complex structures to be generated and to be further used as biologically active systems [7-9].

The use of $\mathrm{Zn}(\mathrm{II}), \mathrm{Co}(\mathrm{II})$ and $\mathrm{Cu}(\mathrm{II})$ metalloporphyrins in PDT arose large attention. So, early this year, porphyrin derivatives, namely: Zn(II)-5,10,15,20-tetrakis(3,4-bis(2-(-2-(2-hydroxyethoxy)ethoxy)ethoxy)benzyl)porphyrin, Zn(II)-5,15-bis(3,4-bis(2-(-2-(2-hydroxy-ethoxy)ethoxy)ethoxy)benzyl)10,20-bis(2-(2-(2-(4-ethynyl-phenoxy)ethoxy)ethoxy)ethanol)-porphyrin and Zn(II)-5,15-bis(3,4-bis(2-(-2-(2-hydroxyethoxy)ethoxy)ethoxy)benzyl)-10,20$\mathrm{N}, \mathrm{N}$-dibutyl-4-ethynyl-aniline porphyrin, were obtained aiming for more efficient cancer treatment. The three $\mathrm{Zn}$-metalloporphyrins were further evaluated in vitro against human carcinoma of the uterine ervix (Hela) cells and exhibited negligible dark toxicity and robust phototoxicity preserving the requirements of cellular uptake [10].

Aiming to design strong near-infrared absorbing porphyrins some porphyrin derivatives substituted with methoxy groups, 5,10,15,20-tetrakis(3,4dimethoxyphenyl) porphyrin, its $\mathrm{Zn}$-derivative and a $\mathrm{Zn}-\mathrm{A}_{2} \mathrm{~B}_{2}$ porphyrin: $\mathrm{Zn}$ (II)5,15-bis(3,4-dimethoxyphenyl)-10,20-bis(4-methoxy-phenyl)ethynyl)porphyrin 
were obtained. The $A_{2} B_{2}$ asymmetrically substituted porphyrin absorbs in the near-infrared (NIR) region, promising to offer the deepest tumor tissue penetration and shows the highest singlet oxygen quantum yield $(79 \%)$ and the best efficacy in vitro on Hela cells [11].

Unsymmetrical porphyrinic complexes with $\mathrm{Cu}(\mathrm{II})$ and $\mathrm{Zn}(\mathrm{II})$ were used in photodynamic therapy of cancer on human histiocytic lymphoma (U937) cell line and did not damage membrane integrity, but acted as cytostatics at higher concentrations, after $24 \mathrm{~h}$ incubation [12]. Functionalized mesotetraphenylporphyrin with two nitro groups were coupled with I-phenylalanine or 1-carboxylmethyl-5-fluorouracil and metalated with $\mathrm{Co}$ (II) or $\mathrm{Mn}(\mathrm{II})$ for further use against cancer stem-like cells from human esophageal carcinoma (Ec9706) cell line in PDT trials [13].

Related to our previous work involving medical investigations on porphyrins [14, 15] our present approach is dealing with comparative cytotoxicity assays performed with a porphyrin base, substituted with methoxy-inductive donor substituents at the phenyl ring in the meso position, namely: $5,10,15,20-$ tetrakis-( $p$-methoxy-phenyl porphyrin (TMeOPP) and with its $\mathrm{Zn}, \mathrm{Co}$ and $\mathrm{Cu}$ complexes (Figure 1). The cytotoxicity evaluation was performed using human (HeLa, 8 MG BA, Lep-3) and bovine (MDBK) cell lines as model systems. The influence of the compounds on cell viability and proliferation was studied by MTT test and further discussed taking into consideration the main optical and aggregation properties of the free porphyrin and its different metal complexes.
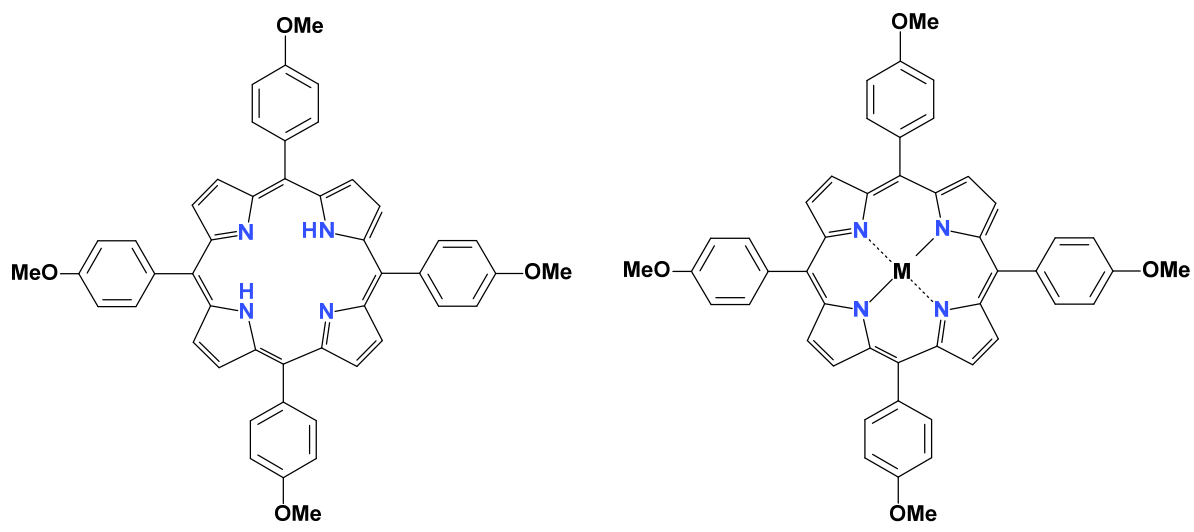

Figure 1. The structures of free base porphyrin TMeOPP and of its metallocomplexes with $\mathrm{M}(\mathrm{II})=\mathrm{Zn}$ (ZnTMeOPP), Cu (CuTMeOPP) and Co (CoTMeOPP).

\section{RESULTS AND DISCUSSION}

The UV-vis spectrum of free porphyrin shown in Figure 2 is a typical porphyrin normal etio spectrum with four visible $(Q)$ bands and an intense Soret (B) band. 
As can be seen in Figure 3, the Soret-band of ZnTMeOPP is redshifted by $6 \mathrm{~nm}$ relative to porphyrin base and all absorbtion bands of ZnTMeOPP are decreased in intensity relative to free porphyrin.

In comparison, the cobalt complex CoTMeOPP is characterized by the same intensity of bands with the porphyrin base, the main diference being the hypsochromic shift of its Soret band with $4 \mathrm{~nm}$. Instead, UV-vis spectrum of CuTMeOPP complex has the same shape with Co complex, a significant hypochromic effect of the main Soret band, but no significant deviation of the Soret band in comparison with porphyrin-base.

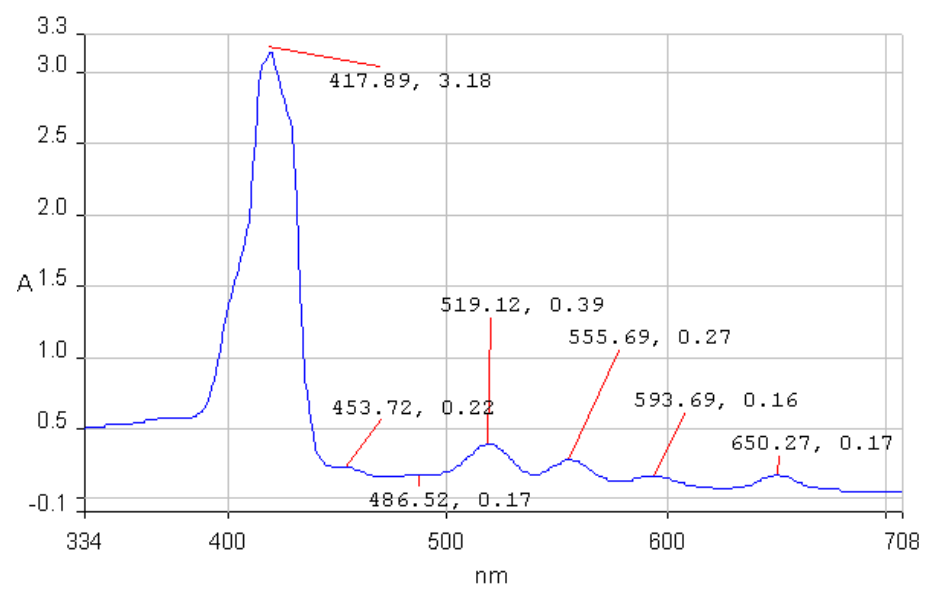

Figure 2. The UV-vis spectrum of tetrakis-(p-methoxy-phenyl)-porphyrin in chloroform

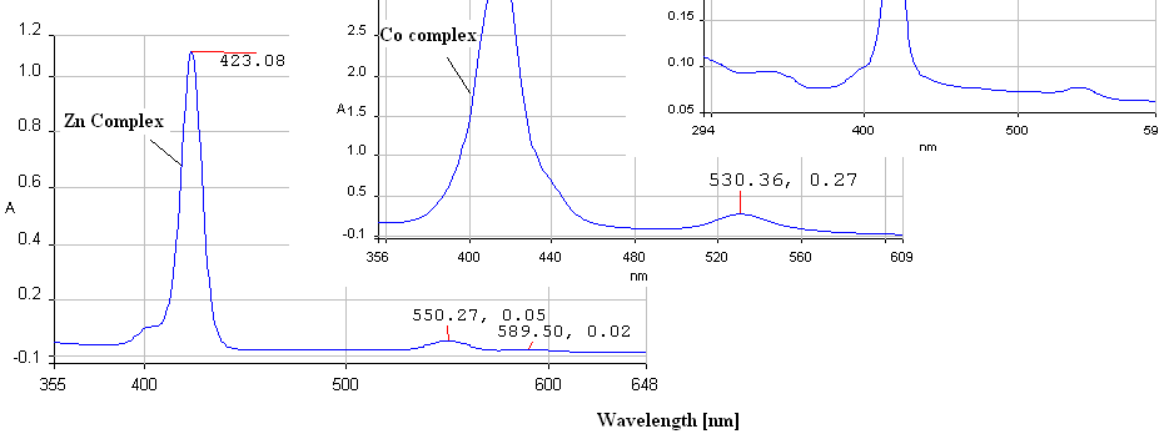

Figure 3. The UV-vis spectra of Zn(II)-; Co(II)- and respectively Cu (II)-tetrakis(p-methoxy-phenyl)-porphyrin, in chloroform 
Microscopic analysis was performed by scanning transmission electron microscopy (STEM) method due to the accurate and versatile information offered, with the aim to compare the aggregation behavior of all the four porphyrin derivatives.

As expected, STEM analysis showed significant differences between the aggregation behavior of the four porphyrin derivatives that we expect to influence their biological activity (Figure 4).
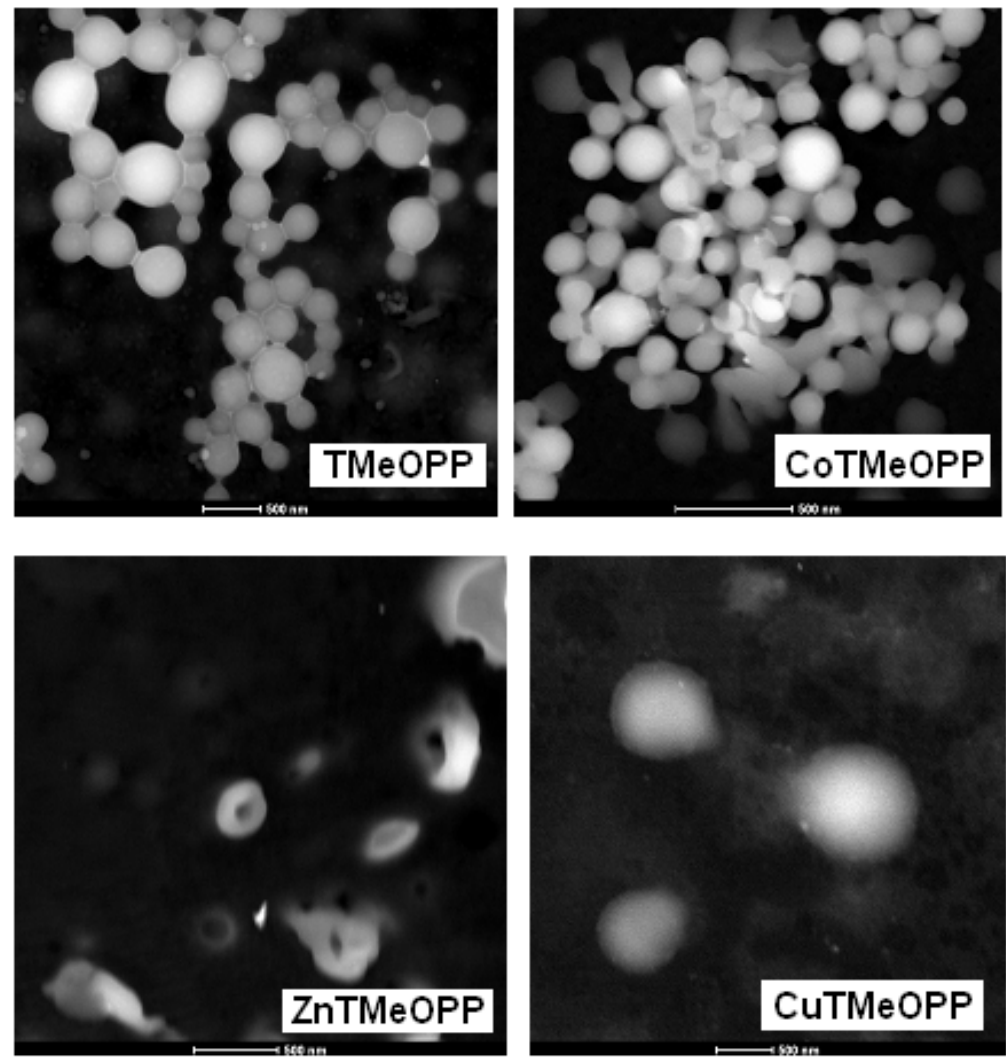

Figure 4. STEM microscopic analysis of porphyrin base TMeOPP and the metalloporphyrins CoTMeOPP, ZnTMeOPP and CuTMeOPP, at the same concentration from DMSO solvent

In both cases of porphyrin base TMeOPP and CoTMeOPP samples the images depicted in Figure 4 show spherical or ovoid aggregates with sizes in the range of $20-50 \mathrm{~nm}$, irregularly connected and forming a mixture of linear and circular agglomerations. Instead, the ZnTMeOPP compound revealed rings of uniform sizes of around $100 \mathrm{~nm}$. The spherical self-aggregates of CuTMeOPP metalloporphyrin, with diameters around 100-150 nm, do not have 
the tendency to agglomerate or link together. All these self-assembling architectures are the result of face to face $\mathrm{H}$-type aggregations and side to side J-type aggregation in which both the porphyrins' meso-substituents and the central metal ion play an important role.

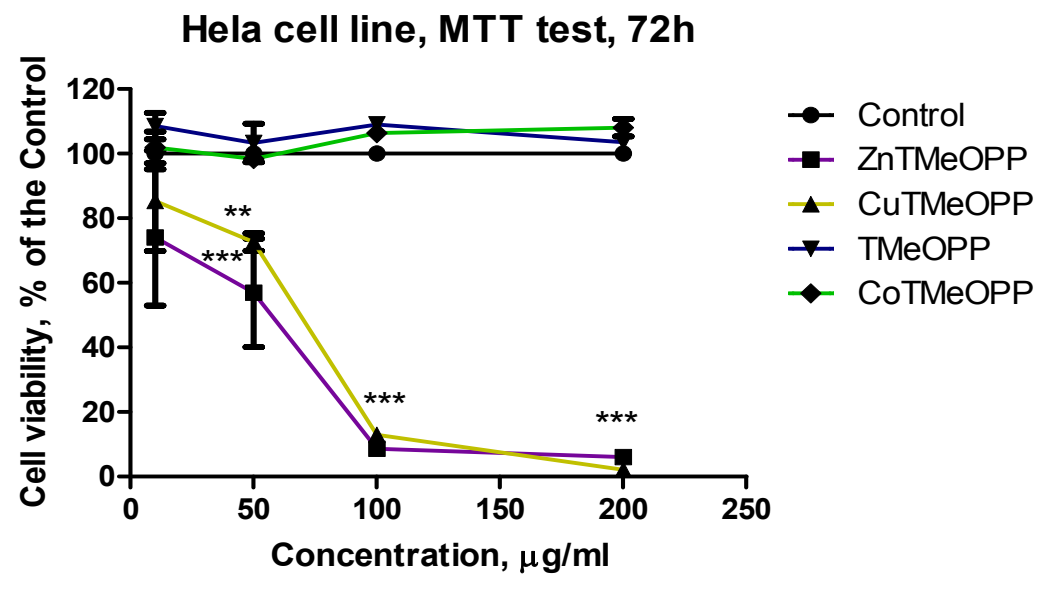

$5 \mathrm{~A}$

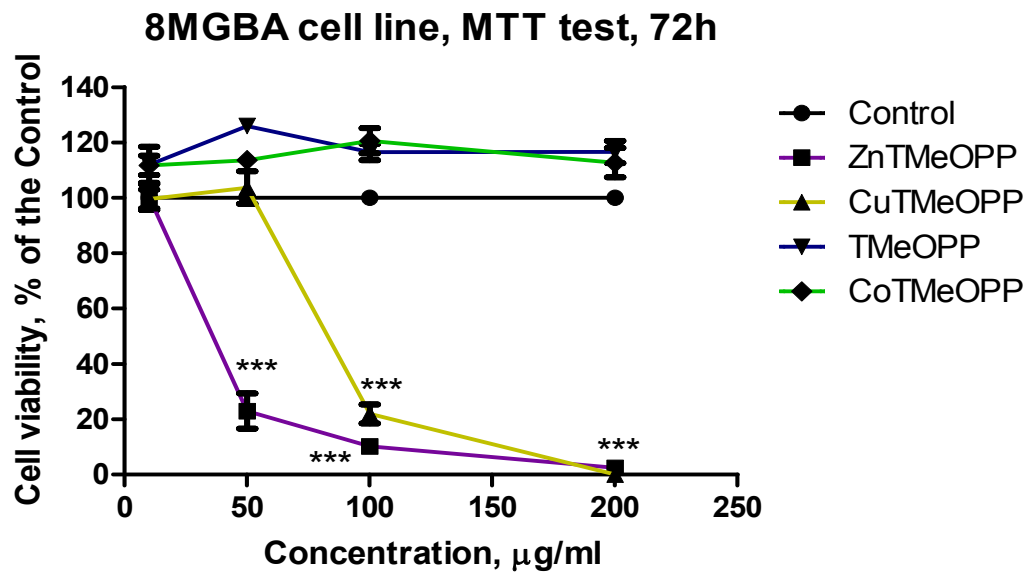

Figure 5. Effect of the investigated compounds on viability and proliferation of cultured human HeLa cervical carcinoma (A) and 8MGBA glioblastoma multiforme

(B) cells. The investigation was performed by MTT test after $72 \mathrm{~h}$ of treatment.

$$
{ }^{* *} P<0.01 ;{ }^{* * *} P<0.001 \text { vs Control }
$$

The cytotoxicity evaluation was performed using human (HeLa, 8 MG BA, Lep-3) and bovine (MDBK) cell lines as model systems. The influence of the compounds on cell viability and proliferation was studied by MTT test 
and further discussed taking into consideration the main optical and aggregation properties of the free porphyrin and its different metal complexes. The results as CC50 and CC90 values $(\mu \mathrm{g} / \mathrm{mL})$ derived from concentration-response curves are given in Table 1. Examples of such concentration-response curves are shown in Figures 5 and 6.

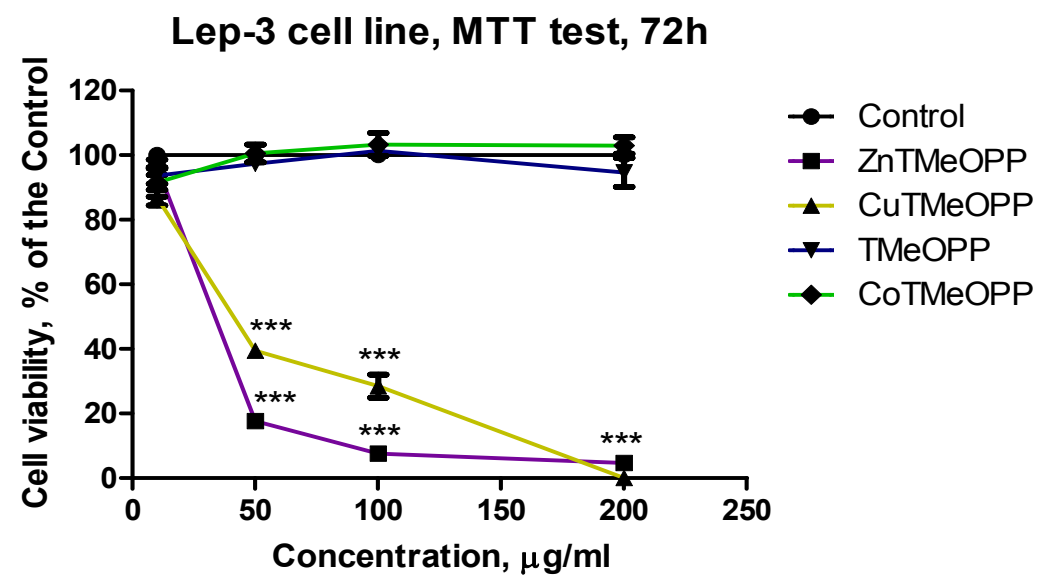

$6 \mathrm{~A}$

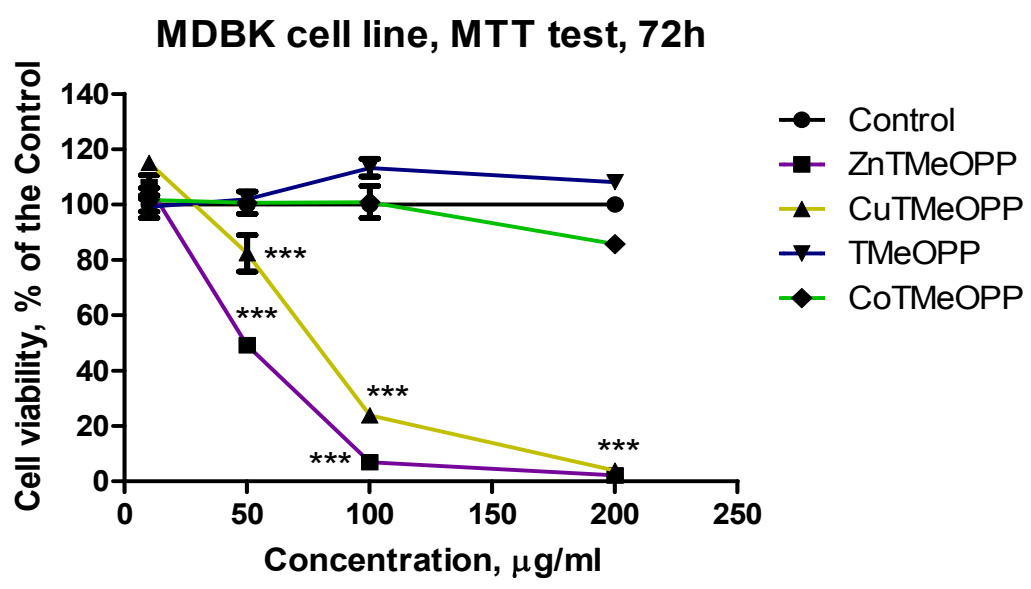

Figure 6. Effect of the investigated compounds on viability and proliferation of cultured non-tumor human Lep-3 (A) amd bovine MDBK (B) cells. The investigation was performed by MTT test after $72 \mathrm{~h}$ of treatment. ${ }^{* \star *} P<0.001$ vs Control 
Table 1. Cytotoxic activity $\left(\mathrm{CC}_{50}\right.$ and $\left.\mathrm{CC}_{90}\right)$ of compounds investigated in human and animal cell lines after 72 hours of treatment

\begin{tabular}{|c|c|c|c|c|}
\hline \multirow{2}{*}{ Cell line } & ZnTMeOPP & CuTMeOPP & TMeOPP & СоTMeOPP \\
\hline & \multicolumn{4}{|c|}{ MTT test, $72 \mathrm{~h}$} \\
\hline HeLa & $\begin{array}{c}57.16^{\star} \pm 2.30 \\
(99.74)^{\star *} \pm 4.81\end{array}$ & $\begin{array}{c}60.06 \pm 3.66 \\
(128.67 \pm 5.28)\end{array}$ & - & - \\
\hline 8MGBA & $\begin{array}{c}36.21 \pm 2.28 \\
(99.14 \pm 3.15)\end{array}$ & $\begin{array}{c}82.72 \pm 4.83 \\
(154.78 \pm 7.18)\end{array}$ & - & - \\
\hline Lep-3 & $\begin{array}{c}79.81 \pm 1.69 \\
(172.96 \pm 3.08)\end{array}$ & $\begin{array}{c}40.78 \pm 2.65 \\
(166.18 \pm 5.04)\end{array}$ & - & - \\
\hline MDBK & $\begin{array}{c}49.78 \pm 2.68 \\
(95.77 \pm 5.42)\end{array}$ & $\begin{array}{c}77.04 \pm 6.14 \\
(170.10 \pm 8.63)\end{array}$ & - & - \\
\hline
\end{tabular}

${ }^{*} \mathrm{CC}_{50}$ and ${ }^{* *} \mathrm{CC}_{90}$ - Cytotoxic concentrations $(\mu \mathrm{g} / \mathrm{ml})$ at which the compounds investigated decrease by $50 \%\left(\mathrm{CC}_{50}\right)$ and by $90 \%\left(\mathrm{CC}_{90}\right)$ the viability of the treated cells as compared to the Control;

( - ) - $\mathrm{CC}_{50}$ was not determined because at all concentrations administered $(1-200 \mu \mathrm{g} / \mathrm{mL})$ the cell viability was $>50 \%$;

The corroborated obtained results on the basis of their ability to decrease viability and proliferation of the treated human and animal tumor and non-tumor cells revealed that the compounds investigated can be divided into two groups: ZnTMeOPP and CuTMeOPP are more pronounced cytotoxic and cytostatic agents as compared to TMeOPPP and CoTMeOPP (Fig. 5; Fig. 6; Table 1).

Some possible explanations for their different cytotoxic behavior arose from their aggregation capacity and the size of the formed aggregates. Based on the STEM microscopy analyses (Figure 4), we can state that $\pi-\pi$ interactions, that are the main factor responsible for the aggregation process in the case of porphyrin base TMeOPP and CoTMeOPP, limit the flexibility of the system.

In addition, as can be seen in Figure 2, the porphyrin base manifests the tendency to form $\mathrm{H}$ aggregates in solution, evidenced by the enlargement of Soret Band and these types of aggregates are considered photoinactive [16].

The lack of large aggregates formation in the case of $\mathrm{Zn}$ and $\mathrm{Cu}$ metalloporphyrins, as revealed by STEM images in Figure 4, favors the cytotoxic activity probably because there is no steric constraint regarding the intake capacity of the cells.

The cytotoxic/cytostatic effects of the compounds examined are dependent of concentration (Table 1; Figures 5 and 6); $\mathrm{CC}_{50}$ for ZnTMeOPP for non-tumor human Lep-3 cells $(79.81 \pm 1.69 \mu \mathrm{g} / \mathrm{ml})$ is higher than $\mathrm{CC}_{50}$ for human tumor HeLa $(57.16 \pm 2.30 \mu \mathrm{g} / \mathrm{ml})$ and $8 \mathrm{MGBA}(36.21 \pm 2.28 \mu \mathrm{g} / \mathrm{ml})$. 
Tested independently, the same amount of DMSO as those in the solutions of the tested compounds has no significant cytotoxic effect as compared to the control - the cell viability was $>94 \%(P<0.05)$.

The efficiency of the metalloporphyrin photosensitizers depends significantly, but not entirely, on the nature of the coordinated central metal ion. The increased cytotoxic activity of ZnTMeOPP might be caused by the core deformation from planar type into more appropriate S4-saddled conformation that was already proven for $\mathrm{Zn}$-porphyrin compounds [17]. It is already known that the distortion of the planarity of the porphyrin macrocycle produces a redshift of the absorption bands, however, this bathochromic shift is accompanied by a decreasing of the extinction coefficients. Nevertheless, non-planar porphyrins act remarkably as biologically active compounds [18, 19]. ZnTMeOPP is also the only metalloporphyrin tested in the present work that manifests a significant bathochromic shift of the Soret-band (Figure 3) in the absorption spectra [20].

\section{CONCLUSIONS}

Comparative cytotoxicity assays were performed with a porphyrin base, namely: 5,10,15,20-tetrakis-(p-methoxy-phenyl porphyrin (TMeOPP) and with its $\mathrm{Zn}(\mathrm{II}), \mathrm{Co}(\mathrm{II})$ and $\mathrm{Cu}(\mathrm{II})$ complexes using human (HeLa, $8 \mathrm{MG}$ BA, Lep-3) and bovine (MDBK) cell lines as model systems. The influence of the compounds on cell viability and proliferation was studied by (thiazolyl blue tetrazolium bromide) MTT test.

The best ability to decrease the viability and proliferation of the treated human tumor cells were manifested by: ZnTMeOPP and CuTMeOPP and the cytotoxic/cytostatic effects for each examined compound depend on concentration.

The efficiency of the metalloporphyrin photosensitizers depends significantly, but not entirely, on the nature of the coordinated central metal ion, the aggregation behavior and the red shifting of the absorption bands.

\section{EXPERIMENTAL SECTION}

\section{Reagents and other materials}

Dulbecco's modified Eagle's medium (D-MEM) and fetal bovine serum (FBS) were purchased from Gibco-Invitrogen (UK). Dimethyl sulfoxide (DMSO) and trypsin were obtained from AppliChem (Germany); thiazolyl blue tetrazolium bromide (MTT) was from Sigma-Aldrich Chemie GmbH (Germany). 
The antibiotics (Penicillin and Streptomycin) for cell cultures were from Lonza (Belgium). Pyrrole, 4-anisaldehyde, propionic acid and acetate salts were provided by Aldrich and Merck (Germany) as purum analiticum reagents. All other chemicals of the highest purity commercially available were purchased from local agents and distributors. All sterile plastic and syringe filters were from Orange Scientific (Belgium).

\section{Synthesized compounds}

Synthesis and purification of 5,10,15,20-tetra(4-methoxy-phenyl) porphyrin (TMeOPP) was done in our laboratory by improving Adler-Longo method [21-23].

Synthesis and purification of $\mathrm{Zn}$, Co and $\mathrm{Cu}$ complexes were done by standard procedures, through metalation reactions of free base TMeOPP porphyrin. The porphyrin-base solution, in dimethylformamide or dichloromethane, was refluxed for 1-2 hours, under vigorous stirring, with a large excess of corresponding metal acetate (20 times more than molar ratio), dissolved in methanol. The reactions were monitored by IR, UV-vis and TLC [24, 25], until the bands corresponding to $\mathrm{NH}$ internal signals were no more present.

The porphyrin and all three metalloporphyrins were fully characterized by UV-vis, FT-IR, H-NMR, TLC, HPLC, MS and fluorescence spectra and were in agreement with previously reported papers [24, 26].

The porphyrinic compounds were initially dissolved in dimethylsulfoxide and then diluted in culture medium. The final concentration of DMSO in the stock solutions (in which the concentration of the tested compound was 1 $\mathrm{mg} / \mathrm{mL}$ ) was $2 \%$.

\section{Apparatus}

FT-IR spectra were registred on a JASCO 430 apparatus as $\mathrm{KBr}$ pellets. 1H-NMR spectra were registered on a $400 \mathrm{MHz}$ Bruker spectrometer in $\mathrm{CDCl} 3$ and chemical shifts were reported relative to internal TMS $(0.0$ ppm). The HPLC analysis was performed on a JASCO apparatus equipped with NUCLEOSIL C18 nonpolar column, 240x4 mm with MD 1510 detector, at ambient temperature. UV-visible spectra were recorded on a UVNIS PERKIN ELMER, LAMBDA 12 spectrometer in $\mathrm{CHCl} 3$ at the same concentration.

The STEM measurements were recorded on Titan G2 80-200 TEM/STEM microscope from FEl Company (The Netherlands) at $200 \mathrm{kV}$ for all the samples prepared on 200 mesh carbon-coated copper grids. The STEM images were obtained using Digital Micrograph v. 2.12 and TEM Imaging \& Analysis v. 4.7 software [27]. 
COMPARATIVE CYTOTOXICITY ASSAYS PERFORMED USING A FREE PORPHYRIN ...

\section{Viability of cell cultures} our study:

The following permanent cell lines were used as model systems in

1. Tumor - HeLa (human carcinoma of the uterine cervix), 8 MGBA (human glioblastoma multiforme);

2. Non-tumor - Lep-3 (3-month old human embryo), MDBK (bovine kidney cells).

The cell lines MDBK and HeLa were purchased from the National Bank for Industrial Microorganisms and Cell Cultures in Sofia, Bulgaria. The cell line Lep-3 was obtained from the Cell Culture Collection of the National Institute of Infectious and Parasitic Diseases in Sofia, Bulgaria. The cell line 8MGBA cell line [28] was a generous gift from Dr. A. Perzelova and Prof. C. Altaner, Cancer Research Institute, Bratislava, Slovakia.

The cells were grown as monolayer culture in D-MEM medium, supplemented with $5-10 \%$ fetal bovine serum, $100 \mathrm{U} / \mathrm{mL}$ penicillin and 100 $\mu \mathrm{g} / \mathrm{mL}$ streptomycin. The cultures were maintained at $37^{\circ} \mathrm{C}$ in a humidified $\mathrm{CO}_{2}$ incubator (Thermo scientific, Hepa class 100). For routine passages adherent cells were detached using a mixture of $0.05 \%$ trypsin and $0.02 \%$ EDTA. The experiments were performed during the exponential phase of cell growth. The cells were seeded in 96-well flat-bottomed microplates at a concentration of $1 \times 104$ cells/well. After the cells were grown for $24 \mathrm{~h}$ to a subconfluent state $(\sim 60-70 \%)$, the culture medium was removed and changed by media modified with different concentrations $(1-200 \mu \mathrm{g} / \mathrm{mL})$ of the compounds tested. Each solution was applied into 4 to 6 wells. Samples of cells grown in non-modified medium served as controls. After $72 \mathrm{~h}$ of incubation, the effect of the compounds on cell viability and proliferation was examined by MTT (thiazolyl blue tetrazolium bromide) test.

The MTT colorimetric assay of cell survival was performed as it was previously described by [29]. Briefly, the method consisted of three hours incubation with MTT solution ( $5 \mathrm{mg} \mathrm{MTT}$ in $10 \mathrm{~mL}$ D-MEM) at $37^{\circ} \mathrm{C}$ under $5 \%$ carbon dioxide and $95 \%$ air, followed by extraction with a mixture of absolute ethanol and DMSO $(1: 1, \mathrm{vol} / \mathrm{vol})$ to dissolve the blue MTT formazan.

Optical density was measured at $540 \mathrm{~nm}$ using an automatic microplate reader (TECAN, SunriseTM, Austria). Relative cell viability, expressed as a percentage of the untreated control (100\% viability), was calculated for each concentration. "Concentration - response" curves were prepared and the effective concentrations of the compounds - CC50 (causing a 50\% reduction of cell viability) and/or CC90 (causing a 90\% reduction of cell viability) were estimated (where possible) from these curves using Origin 6.1. All data points represent an average of three independent assays. 


\section{Statistical analysis}

The data are presented as mean \pm standard error of the mean. Statistical differences between control and treated groups were assessed using one-way analysis of variance (ANOVA) followed by Dunnett post-hoc test and Origin 6.1TM.

\section{ACKNOWLEDGMENTS}

This study was supported by grant № DFNI Б-02/30 from 12.12.2014, National Science Fund, Bulgarian Ministry of Education and Science and a bilateral project between Bulgarian Academy of Sciences and Romanian Academy. Romanian authors are also acknowledging Romanian Academy for financing the Programmes 3 / 2018 from ICT.

\section{REFERENCES}

1. J. F. Lovell, T.W.B. Liu, J. Chen, G. Zheng, Chemical Reviews, 2010, 110(5), 2839.

2. G. Yu, T. Durduran, C. Zhou, T.C. Zhu, J.C. Finlay, T.M. Busch, S.B. Malkowicz, S.M. Hahn, A.G. Yodh, Photochem. Photobiol. 2006, 82, 1279.

3. W. Li, D. Huang, Y. Zhang, Y. Liu, Y. Gu, Z. Qian, Ann. Biomed. Eng. 2016, 44, 2737.

4. E. Fagadar-Cosma, C. Enache, R. Tudose, I. Armeanu, E. Mosoarca, D. Vlascici, O. Costisor, Revista de Chimie-Bucharest, 2007, 58(5), 451.

5. B. Pucelik, R. Paczyński, G. Dubin, M.M. Pereira, L.G. Arnaut, J.M. Dąbrowski, PLoS ONE 2017, 12(10), e0185984 https://doi.org/10.1371/journal.pone.0185984.

6. V.F. Otvagin, A.V. Nyuchev, N.S. Kuzmina, I.D. Grishin, A.E. Gavryushin, Y.V. Romanenko, O.I. Koifman, D.V. Belykh, N.N. Peskova, N.Y. Shilyagina, I.V. Balalaeva, A.Y. Fedorov, European Journal of Medicinal Chemistry, 2018, 144 (20), 740.

7. E. Fagadar-Cosma, I. Sebarchievici, A. Lascu, I. Creanga, A. Palade, M. Birdeanu, B. Taranu, G. Fagadar-Cosma, Journal of Alloys and Compounds, 2016, 686, 896.

8. E. Fagadar-Cosma, E. Tarabukina, N. Zakharova, M. Birdeanu, B. Taranu, A. Palade, I. Creanga, A. Lascu, G. Fagadar-Cosma, Polymer International, 2016, 65(2), 200.

9. E. Fagadar-Cosma, G. Fagadar-Cosma, M. Vasile, C. Enache, Current Organic Chemistry, 2012, 16, 931.

10. D. Pan, X. Zhong, W. Zhao, Z. Yu, Z. Yang, D. Wang, H. Cao, W. He, Tetrahedron, 2018, 74(21), 2677.

11. K. Ding, Y. Zhang, W. Si, X. Zhong, Y. Cai, J. Zou, J. Shao, Z. Yang, X. Dong, ACS Applied Materials and Interfaces, 2018, 10 (1), 238. 
12. R. Socoteanu, M. Anastasescu, G. Dobrescu, R. Boscencu, G. Vasiliu, C. Constantin, Chaos, Solitons and Fractals, 2015, 77, 304.

13. S. Weimin, Z. Gen, D. Guifu, Z. Yunxiao, Z. Jin, T. Jingchao, Bioorganic and Medicinal Chemistry, 2008, 16 (10), 5665.

14. S. L.Trancota, C. Enache, O. Duicu, S. N. Mirica, E. Făgădar-Cosma, D. Muntean, Archives of Cardiovascular Diseases, 2011, Supp/ 3, 31.

15. E. Fagadar-Cosma, L. Cseh, V. Badea, G. Fagadar-Cosma, D. Vlascici, Combinatorial Chemistry \& High Throughput Screening, 2007, 10 (6), 466.

16. L.B. Josefsen, R.W. Boyle, Metal-Based Drugs, 2008, Article ID 276109, 24 pages.

17. N. Mehraban, H. Freeman, Materials, 2015, 8(7), 4421.

18. B. Röder, M. Büchner, I. Rückmann, M.O. Senge, Photochem. Photobiol. Sci. 2010, 9, 1152.

19. B. L. Josefsen, R. W. Boyle, Theranostics, 2012, 2(9), 916.

20. A. Wiehe, H. Stollberg, S. Runge, A. Paul, M. O. Senge, B. Roder, Journal of Porphyrins and Phthalocyanines, 2001, 5, 853.

21. A.D. Adler, F.R. Longo, J. Goldmacher, J. Assour, L. Korsakoff, J. Org. Chem., 1967, 32, 476.

22. L. Xiangqing, $\underline{W}$. Xingqiao, S. Yingya, G. Jingfu, D. Jiangwen, L. Guofa, Chemistry Magazin Organic 2001, 3, 37.

23. Z. Jing, G. Yang, C. Shaokui, Z. Wennan, W. Dongmei, C. Huifang, L. Tianxuan, Chemistry Magazin Organic, 2002, 8, 39.

24. M. E. Milanesio, M. G. Alvarez, E. I. Yslas, C. D. Borsarelli, J. J. Silber, V. Rivarola, E. N. Durantini, Photochemistry and Photobiology, 2001, 74(1), 14.

25. E. Fagadar-Cosma, I. Creanga, B. Maranescu, A. Palade, A. Lőrinczi, G. FagadarCosma, M. Popescu, Digest Journal of Nanomaterials and Biostructures, 2011, 6, 75.

26. D. Vlascici, E. Fagadar-Cosma, O. Bizerea-Spiridon, Sensors (Basel), 2006, 6(8), 892.

27. I. Sebarchievici, A. Lascu, G. Fagadar-Cosma, A. Palade, I. Fringu, M. Birdeanu, B. Taranu, E. Fagadar-Cosma, Compt. Rendus Chimie, 2018, 21(3-4), 327.

28, Perzelová A., I. Máciková , P. Mráz , I. Bízik, J. Steno, Neoplasma, 1998, 45(1), 25.

29. L. Dyakova, D. C. Culita, G. Marinescu, M. Alexandrov, R. Kalfin, L. Patron, R. Alexandrova, Biotechnology, Biotechnological Equipment, 2014, 28 (3), 543. 
